\title{
Optimization of copper ammonium etching composition solutions in the production of printed circuit boards
}

\author{
(C) Ekaterina P. Boyarskih, Ludmila A. Brusnitsina, ${ }^{+}$ \\ Elena I. Stepanovskih, and Tatiana A. Alekseeva \\ Physical Chemistry and Chemistry of Colloids Academic Department. \\ Ural Federal University Named after the First President of Russia B.N. Yeltsin. \\ Mira St., 19. Yekaterinburg, 620002.Russia.E-mail: brusnitsyna.l@yandex.ru
}

\begin{abstract}
*Supervising author; ${ }^{+}$Corresponding author
Keywords: metal copper etching, copper(II) ammonia complexes, etching speed, release layer thickness, printed circuit boards.
\end{abstract}

\begin{abstract}
Etching in the production of printed circuit boards is the process of chemical destruction of metal (mainly copper) as a result of the action of liquid or gaseous etchers on the areas of the surface of the workpiece unprotected by a protective mask (etching resist). Copper foil etching is used to form a conductive pattern of PCB by removing copper from unprotected etching resist areas. This is one of the main operations of manufacturing the PCB, since a pattern of printed elements is formed on it.

During the etching process, unprotected copper from the printed circuit board by means of an oxidizer is converted into an ionic state and is connected to hydroxide and ammonium chloride, forming a solution of the copper-ammonia complex, which after oxidation with air ensures dissolution of copper.

The etching solution in question contains three components: copper(II) chloride, which when reacted with metallic copper is an oxidant; Ammonia forming ammonia complexes with copper(II) and allowing copper(II) to be kept in a soluble state; Ammonium chloride, which accelerates the etching process and keeps the solution stable. Increased efficiency of copper etching in ammonia solutions is achieved at change of its composition.

The purpose of the work was to study the etching rate of copper and to change the concentration of the etching solution depending on the initial concentration of copper(II) chloride in the original etching solution, as well as the effect of the $\mathrm{pH}$ of the etching solution on the etching rate of metallic copper.

The double-sided foamed fiberglass was used as a starting material to study the etching process. The foil thickness was $30 \mu \mathrm{m}$. Etching of the copper foil was carried out with constant stirring of the sample in solution.

The concentration of copper ions in the solution was determined by spectrophotometric method from the value of optical density of the ammonia-containing solution (D). The thickness of the release layer of metallic copper was determined by gravimetric method.

As a result of this work, it has been shown that changes in the concentration of copper(II) in the solution, the etching rate, the thickness of the release coating and the $\mathrm{pH}$ of the solution can be used to characterize the copper etching process.

It is established that the greatest increase in concentration of $\mathrm{Cu}^{2+}$ in solution is observed within the first minute with its further gradual slow increase. More obvious increase in concentration of $\mathrm{Cu}^{2+}$ in solution is observed at concentration of $\mathrm{Cu}^{2+}$ in initial solution $80 \mathrm{~g} \cdot 1^{-1}$.

At increase in concentration of chloride of copper(II) in solution from $40 \mathrm{~g} \cdot \mathrm{l}^{-1}$ to values $100 \mathrm{~g} \cdot \mathrm{l}^{-1}$ sharp increase in speed of etching of copper is observed. A further increase in copper(II) chloride concentration results in a decrease in etching rate.

The $\mathrm{pH}$ of the etching solution is determined by the ratio of ammonia and ammonium chloride. This is due to the formation of a buffer mixture in the solution. Increasing the $\mathrm{pH}$ of the solution results in an increase in the etching rate followed by a decrease in the etching rate.
\end{abstract}

\section{References}

[1] M. Otto. Modern methods of analytical chemistry. Moscow: Technosphere. 2006. 543p. (russian)

[2] V.P. Vasilyev. Analytical Chemistry. Moscow: Bustard. 2004. 384p. (russian)

[3] A.M. Medvedev. Technologies of printed circuit boards production. Moscow: Technosphere. 2005. 360p. (russian) 
OPTIMIZATION OF COPPER AMMONIUM ETCHING COMPOSITION SOLUTIONS IN THE PRODUCTION... 36-42

[4] V.A. Ilin. Manufacturing technology of printed circuit boards. Leningrad: Mechanical engineering. 1984. 77 p. (russian)

[5] V. Tereshkin, J. Fantgof, L. Gregory. Etching of printed circuit boards and regeneration of etching solutions. Technologies of electronic industry. 2007. No.3. P.26-29. (russian)

[6] Short Handbook on Chemistry. Edited by O.D. Kurilenko. 1974. 984p. (russian)

[7] A.G. Stromberg. Physical Chemistry. Moscow: The higher school. 2009. 527p. (russian) 